\title{
The key role of nutrition in controlling human population dynamics
}

\author{
C. J. Duncan and S. Scott* \\ School of Biological Sciences, University of Liverpool, Life Sciences Building, Liverpool L69 7ZB, UK
}

\begin{abstract}
The early hominids and their successors, the nomadic hunter-gatherers, were evolutionarily adapted to an omnivorous diet. Their food was well balanced nutritionally and they acquired adequate supplies with relatively little expenditure of energy. The complete change to a fixed agricultural lifestyle (the Neolithic revolution) took place only some 12000 years ago and was the most momentous event in human history. Being tied to the land that they worked led eventually to the city states and the great civilisations of history, which brought with them wars and epidemics of infectious diseases. Much more serious were the insidious effects of the new cereal-based diet which persisted until the twentieth century. Not only was it labour intensive, but also for the bulk of the population it was often deficient in vitamins, minerals and energy, particularly at certain times of the year. Time-series analysis reveals a regular short wavelength oscillation in the grain supply that persisted for at least 350 years and dominated the population dynamics of pre-industrial England. In addition to reducing fertility, it acted primarily via its effects on the nutrition of the pregnant woman. Malnutrition during one of the critical trimesters of pregnancy could have far-reaching effects not only on the health of the fetus and neonate but also on the illnesses of later, adult life. These consequences were insidiously and inevitably carried forward to the subsequent generations. Girls who were born with a low birth weight produced daughters and granddaughters of low birth weight, irrespective of their nutrition during childhood. These intergenerational, knock-on effects established a vicious circle from which there was little chance of escape.
\end{abstract}

Human population dynamics: Malnutrition: Maternal nutrition: Fetal nutrition: Fertility

\section{Introduction}

'Virtually every major anatomical change ... can be related in one way or another to how foods are acquired and processed in the human body. Indeed, the very fact that our human-like ancestors had acquired a bipedal manner of walking by some five to eight million years ago is almost certainly related to how they acquired food.' (Larsen, 2000) The earliest hominids inherited from their primate ancestors a dentition and digestive system that were adapted to the omnivorous diet of the hunter-gatherer lifestyle. The change to an agricultural means of obtaining food was the most important event in our history. Although it was inevitable and brought many benefits, the new grain-based diet was sub-adequate for most individuals and dominated human population dynamics for some 12000 years.

\section{The value of time-series analysis}

Most long-run series of data, such as weather, grain prices, sunspot activity, predator-prey numbers, mortality, births or epidemics, exhibit fluctuations, although these may not be readily discernible by eye. Where the fluctuations are regular, the data series becomes really interesting and raises questions about what causes these cycles and how they are driven.

Time-series analysis is a valuable computer-based statistical technique that can be applied to phenomena that fluctuate or oscillate regularly with time. The standard oscillation (or cycle) considered by physicists and mathematicians is a sine wave (generated by plotting the sine of an angle against the angle itself); a household example is the sine-wave oscillation of the AC mains.

The wavelength $(\lambda)$ is the time taken for one complete oscillation and is measured from cycle peak to cycle peak. An oscillation is defined by its frequency, i.e. the number of complete cycles in unit time (for example, cycles/s; middle $\mathrm{C}$ is a vibration at $256 \mathrm{cycles} / \mathrm{s})$. From this it follows that the frequency $=1 / \lambda$.

It will be shown that a number of characteristic oscillations can be detected in the time series of baptisms and burials and, since several oscillations are present together 
but are driven independently, the resulting fluctuations are difficult to distinguish. Furthermore, since these series represent human behaviour, the initial picture is inevitably confusing. Such cycles are described as 'noisy'. It is the function of time-series analysis to eliminate the noise and to distinguish the individual oscillations contained therein. The time series may also show gradual shifts or movements to relatively higher or lower values over a longer period of time. This gradual shifting is usually due to long-term factors such as, for example, changes in population size, changes in the demographic characteristics of the population, or changes in technology and is referred to as the trend in the series (see Fig. 1).

We have used the MATLAB packages (The MathWorks, Natick, MA, USA) where the following programs are available: spectral analysis; filtering; cross-correlation function.

\section{Spectral analysis}

This program analyses a complex and noisy series (for example, the annual number of infant burials in a population) and identifies the regular oscillations hidden therein, defining each by their wavelength (i.e. the number of years for one complete cycle). The program also analyses the relative strength of the different cycles and (most valuably) determines their statistical significance.

\section{Filtering}

Once an oscillation has been identified, a filter can be designed which eliminates the noise and all other cycles, leaving only the oscillation at the desired wavelength. The filter window defines the wavelength of the oscillations that are not filtered out. Examples of the display are shown in Figs. 1, 3 and 8. This program is a statistical sophistication of the moving average technique.

\section{Cross-correlation function}

This program compares and cross-correlates two time series. For example, it estimates whether annual wheat prices drive annual burials. Two filtered data series are fed into this program which compares them over a standard time period; it provides an indication of the significance of the correlation between them and of the delay (or lag) between the two cycles. Zero lag indicates that the two oscillations are synchronous. An example of a printout of a cross-correlation function is shown in Fig. 5.

\section{Evolution of the human digestive system}

The cradle for human evolution was the Great Rift Valley in Ethiopia and Kenya, and primates with definite humanlike features had developed by about 4.5-5 million years ago. It is reasonable to speculate that these higher primates were able, when climatic conditions were unfavourable and the forests were receding, to increase their food repertoire by applying their knowledge and skills to hunting and searching for food away from tree cover. They had inherited a chimpanzee-like, omnivorous digestive system and tiny marks on the teeth of early australopithecine species suggest that they ate fruit. However, like their chimpanzee

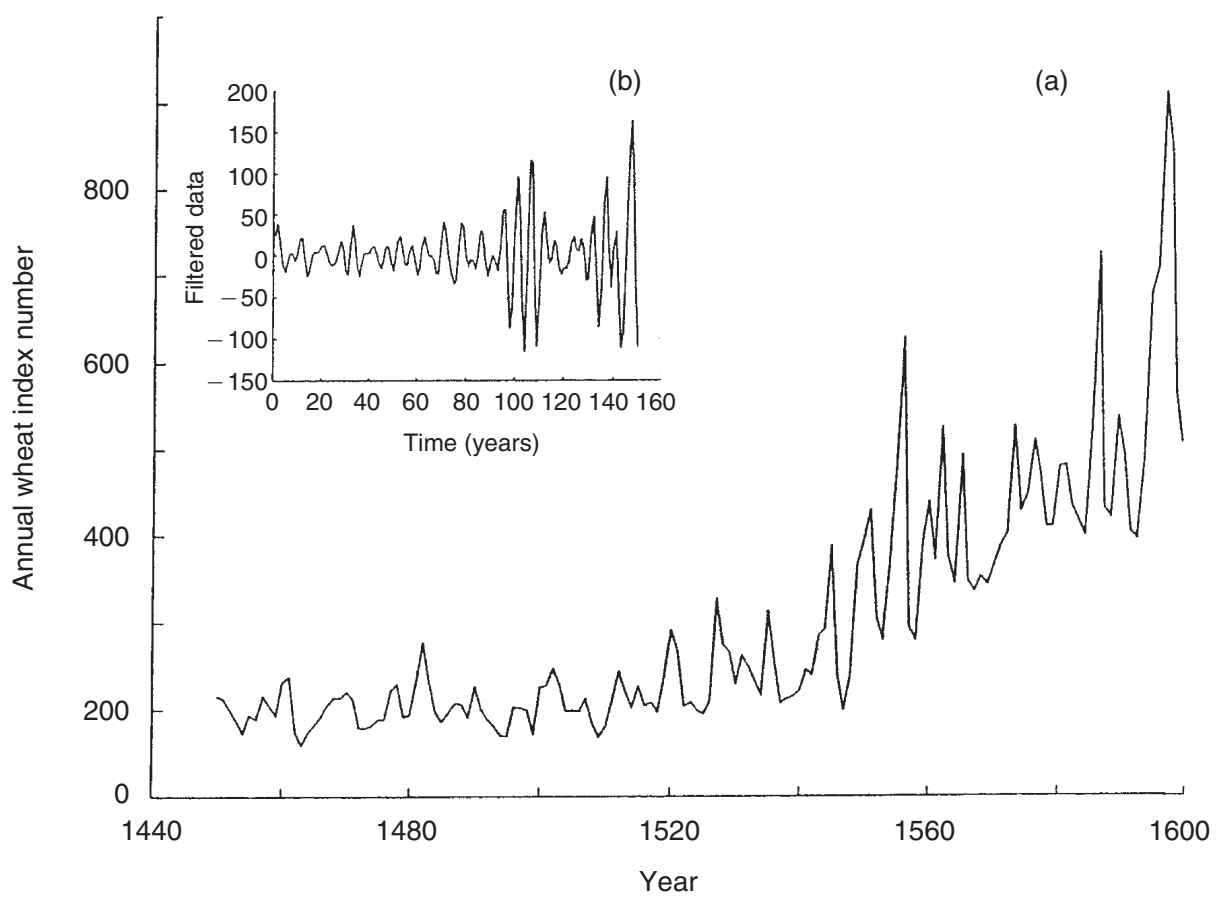

Fig. 1. (a) Annual national wheat prices (wheat index number) for the early years, 1450-1599, showing the rising trend and the emergence of a short wavelength oscillation after 1540. (b) Annual wheat prices, 1450-1599, filtered to reveal the short wavelength oscillations (filter window of 4-10 years). (After Bowden, 1967.) 
and gorilla ancestors they probably also ate vegetable matter and took eggs, insects, lizards and other small creatures if they were easily available.

About 2 million years ago the first true man (Homo habilis) appeared; this species used tools, with meat forming a substantial part of the diet. At first this was probably acquired through a strategy involving scavenging rather than deliberate hunting. Thus, our ancestral feeding pattern was established some 4 million years ago, during which time our digestive system, with a short colon and no rumen, and the underlying dietary physiology and biochemistry slowly adapted to maximum efficiency for handling this generalised diet. The increase in brain size in later hominids correlates neatly with a shift to a more carnivorous dentition and skull structure.

\section{Emergence of the hunter-gatherers}

The full hunter-gatherer lifestyle began about 700000 years ago and was characterised by the deliberate hunting of animal food sources (Larsen, 2000). Archaic H. sapiens probably evolved from $H$. erectus between 500000 and 200000 years ago, with the first anatomically modern man, who probably made increasing use of fire for cooking, appearing about 125000 years ago. Behaviourally, modern man first appeared in the fossil record 40000 years ago and there have been no significant changes since then. The Late Palaeolithic period (40 000-10 000 BC) saw the culmination of universal hunter-gathering and the use of seafood becomes evident in certain areas. The design of the dentition, with both slashing and grinding teeth, was clearly adapted for this omnivorous diet.

The huge mammoths and rhinoceroses were disappearing when $H$. sapiens was fully established, but they were hunting a wide range of animals, which they found around them. They moved around the local area on a seasonal basis, travelling to wherever they could find suitable prey (Klein, 1989). In central Europe, they made sewing tools, harpoons and spear throwers. Their main food animals were reindeer, horses and much fish. Seals were also caught and they trapped large numbers of arctic grouse and hares in winter. They may also have eaten the half-digested sour mash in the stomachs of hunted reindeer; this vegetable supplement to the diet, derived from the lichens on which the reindeer grazed, is a rich source of vitamins and iodine, and is used by Siberians today. Later, plants appeared in the artwork on the walls of their caves, perhaps indicating the importance of vegetable matter in their food and the dawn of the interest in agriculture. They apparently ate some fruits, nuts, roots of vegetables, leafy vegetables, and berries seasonally.

These small, mobile groups living on wild foods enjoyed well-balanced and varied diets and relatively good health. There was generally a ready supply of nutritious food with an adequate content of vitamins and minerals. Indeed, everything suggests that their diets remained well balanced even when they were low in energy. Most importantly (for them) their food was usually very low in sugars although, at certain times of the year, they may have consumed significant amounts from the fruit in their diet. These prehistoric hunter-gatherers became tall, well muscled and strong with large heads. Many of the males stood six feet high (Cohen, 2000).

The human gut has evolved over a period of the last 4 million years to be shorter and to be more dependent on nutrient- and energy-dense foods than other primates. The brain steadily increased in size concurrent with the reduction in the size of the human gut. Sufficient amounts of long-chain fatty acids in the diet, present in their animal prey, were essential to support brain growth during human evolution. Mobility was one of the distinguishing characteristics of the hunter-gatherers. When all the food was exhausted in their patch, they moved on to a new temporary home territory. The pattern of their movements was also governed by the seasons; they always travelled to places where they could find food.

\section{Hunter-gatherer communities today}

There are more than fifty foraging societies that have persisted in the world today and many reflect the prehistoric hunter-gatherer lifestyle. Some, such as the !Kung San hunter-gatherers of the Kalahari desert in southern Africa, have been studied intensively. The diet of the San consists of an eclectic, yet selective, collection of wild foods (mostly vegetable) eaten fresh. They consume twenty-three of eighty-five plant species that they know to be edible in their environment and seventeen of fifty-five edible animal species. Daily animal protein intake is approximately 30-50 g/head per $\mathrm{d}$, which greatly exceeds an estimated average of 7-10 g animal protein/head per $\mathrm{d}$ in modern developing countries. Each individual in the group receives sufficient protein, vitamins and minerals and there is no medical evidence of malnutrition (Lee, 1968, 1969; Cohen, 2000).

Societies such as the Hadza of Tanzania, who live in a far richer foraging area, consume between 50 and $250 \mathrm{~g}$ meat protein/head per $\mathrm{d}$ and they probably reflect better the lifestyle of the prehistoric hunter-gatherers (Woodburn, 1968).

Animal sources of protein contain all essential amino acids in the correct proportions; they are a primary source of vitamin $B_{12}$, are high in vitamins $A$ and $D$, and contain important minerals. Moreover, animal fat is a critical source of essential fatty acids and fat-soluble vitamins. Obviously, vegetarian diets vary greatly but as a generalisation, relative to the cereal-based diet of the later agriculturalists, meat is a highly nutritional food resource. The enormous differences between the diets of the hunter-gatherers of the Palaeolithic and the nutritional recommendations today are illustrated in Table 1.

It is striking that such a large proportion of energy was provided by protein in the hunter-gatherer diet. The daily intake of vitamins, minerals and fibre seems to be unimaginably high and unachievable through modern-day diets. Some researchers go further. They estimate from their survey of hunter-gatherer populations that, whenever and wherever possible, 45-65\% of the energy in their diets came from animal foods.

The modern !Kung San hunter-gatherers of the Kalahari desert consume much more meat and, hence, potentially more saturated fats than is recommended by modern medi- 
Table 1. Comparison of estimated Palaeolithic diet with US dietary recommendations (Nestle, 2000)

\begin{tabular}{lcc}
\hline & $\begin{array}{c}\text { Palaeolithic } \\
\text { diet }\end{array}$ & $\begin{array}{c}\text { US dietary } \\
\text { recommendations }\end{array}$ \\
\hline Protein (\% energy) & 37 & 12 \\
Carbohydrate (\% energy) & 41 & 58 \\
Fat (\% energy) & 22 & 30 \\
Cholesterol (mg/d) & 480 & 300 \\
Fibre (g/d) & 104 & $20-35$ \\
Vitamin C (mg/d) & 604 & 60 \\
Vitamin E (mg/d) & $32 \cdot 8$ & $8-10$ \\
Fe (mg/d) & $87 \cdot 4$ & $10-15$ \\
Energy (kJ) & 12560 & $9210-12140$ \\
\hline
\end{tabular}

cine and yet medical checks show that they have very low blood cholesterol levels and virtually no heart disease. The reason for this paradoxical result is that hunter-gatherers eat lean, free-range meat.

The hunter-gatherers probably balanced their high-protein diet with variable amounts of fruit and nuts. A recent study of women who had eaten the high level of $0.45 \mathrm{~kg}$ red meat/d and had avoided carbohydrate-rich foods during pregnancy showed that the offspring had higher blood pressure in adult life (Shiell et al. 2001).

One thing is clear; both the prehistoric and contemporary hunter-gatherers usually enjoyed an adequate and wellbalanced nutrition and they achieved this with a relatively light workload (Woodburn, 1968; Cohen, 2000; Larsen, 2000).

But this way of life with a balanced and nutritious diet to which they had become fully adapted by evolution was to change completely. Nomadic hunting and gathering gradually gave way to the universal adoption of an agricultural lifestyle. Cultural man has been on earth for about 2 million years and for $99 \%$ of this time he has lived as a hunter-gatherer. Man began to domesticate plants and animals only in the last 10000 years. To date, however, the hunting way of life has been the most successful and persistent adaptation that man has ever achieved.

\section{The Neolithic revolution and its consequences}

About 10000 years ago man quit the nomadic hunter-gatherer lifestyle and adopted a fixed mode of existence by obtaining food from the surrounding fields. This dramatic change is termed the Neolithic revolution and was the most important event in the 2 million years of human history. Once man became fixed to living beside growing crops, little communities gradually became established and longterm stability and cooperation over land clearance and defence became possible. The aggregation into early townships led eventually to the foundation of the city states and the flowering of the great civilisations of the Nile and Indus valleys and the Greek, Roman and Byzantine empires.

Thus, the essential material foundations of civilisation were entirely based on the means of obtaining food; cereals and livestock farming, and improving the stocks of both plants and animals by selective breeding. Man did not develop the arts and technology of civilised life until a food-gathering culture had been passed and the stage of food producing had been reached. This dramatic transfor- mation was achieved in less than 10000 years; and there have been no significant genetic changes during the last 40000 years and agriculture has not had any impact on our evolution.

But this remarkable success story had its downside. The workload of this agricultural lifestyle was very much greater than that required of the hunter-gatherers; killing one large animal would have kept the group in food for a long time. A hectare of land produced more energy per annum when cultivated than when exploited by the hunter-gatherers, but the price they paid was severe. Several of the effects acted together to limit and control the growth of populations. With the aggregation of individuals into towns, living closely together, epidemics of infectious diseases appeared and scourged the populations. This horror reached its climax in the fourteenth century with the appearance of the Black Death and the plagues persisted for the next 300 years and very effectively controlled population expansion in Europe. Once the plagues had disappeared forever they were replaced by other deadly epidemics such as smallpox in the towns and cities of Europe. Furthermore, measles and whooping cough remain as serious infectious diseases among the poorly nourished children of Third World countries today.

Disease and wars were two of the inevitable and terrible consequences of the Neolithic revolution but they were not the most serious for the history of mankind. The new, cereal-based diet with only a small additional amount of animal protein for most individuals usually provided a nearly sufficient daily intake of energy to carry out the heavy workload in the fields for much of the year. But it was completely lacking the variety of the hunter-gatherer's menu and, consequently, was unbalanced and, even worse, was probably deficient during pregnancy in some minerals $(\mathrm{Fe}, \mathrm{Zn}$ and $\mathrm{Cu})$, protein and vitamins (A, C, D and folate) at critical times.

Furthermore, the human digestive system was not evolutionarily adapted to this new diet. So, the effects were insidious, but they had serious and far-reaching consequences and dominated human population dynamics for the next 10000 years.

\section{The dangers of a fluctuating food supply}

The prehistoric hunter-gatherers were little affected by the seasons of the year. True, they followed their quarry if they moved their feeding grounds over winter and what they were able to gather would change with the seasons. But, by and large, they had a well-balanced diet throughout the year. All this was to change when man adopted a cerealbased agricultural lifestyle. Not only were there ties to the plots of land that had been cultivated, but also there was critical dependence on the one period in the year when the crops were harvested. Food was in abundance at this time, but forward planning was essential. The precious grain had to be stored because it must last for the next 12 months; it was the major food supply. And some grains had to be set aside for sowing next year.

The supply of staple grain usually ran out and, with only limited supplies of alternative food available, the weeks preceding the next harvest became known as the hungry 
season. The harvest required the greatest effort from all members of the community and this was the time of the year when they carried the heaviest workload. Unfortunately for them, they had to meet these demands just when they had been on the edge of starvation and were sadly undernourished. Moreover, these farmers were completely dependent on the weather. A bad growing season or prolonged rain before harvest could destroy all their work through the year. They faced starvation. And there would be no seed-grain for the following year.

There is little strict quantitative data concerning the success of the annual harvest in England until the fifteenth century when integrated markets for the sale of the staple grains began to appear and agriculture was established on an economic basis. An annual average price for each of the major grains was declared (Bowden, 1967, 1985) and cross-correlation functions show that the prices of wheat, barley and oats were significantly correlated $(P<0 \cdot 001)$; i.e. if there was a bad wheat harvest the prices of the other grains also rose. The country existed on an economic tightrope and, if there was a shortage of wheat, everyone scrambled for the poorer grains (Hoskins, 1964; Scott \& Duncan, 1998).

The annual wheat prices remained steady from 1450 to 1550 , but thereafter rose steadily. The price quadrupled in 50 years, causing malnutrition and near-starvation in the working classes who formed the bulk of the population (Fig. 1). After 1600, the baseline steadied again and showed a slight downward trend during the next 150 years (Fig. 2).

Figs. 1 and 2 disguise a much more sinister effect; the annual price of wheat, which formed the staple diet, fluctuated sharply on a very regular basis. These short wavelength oscillations emerged clearly after 1550 (see Fig. 1 (b)). Spectral analysis shows a significant periodicity of 5-6 years $(P<0 \cdot 001)$ for $1550-1750$, which is clearly revealed after filtering (Fig. 3).

The working classes in England had, therefore, to contend not only with an overall poor and unsatisfactory diet, but also with a regular and sharp fluctuation in the price and availability of their staple food.

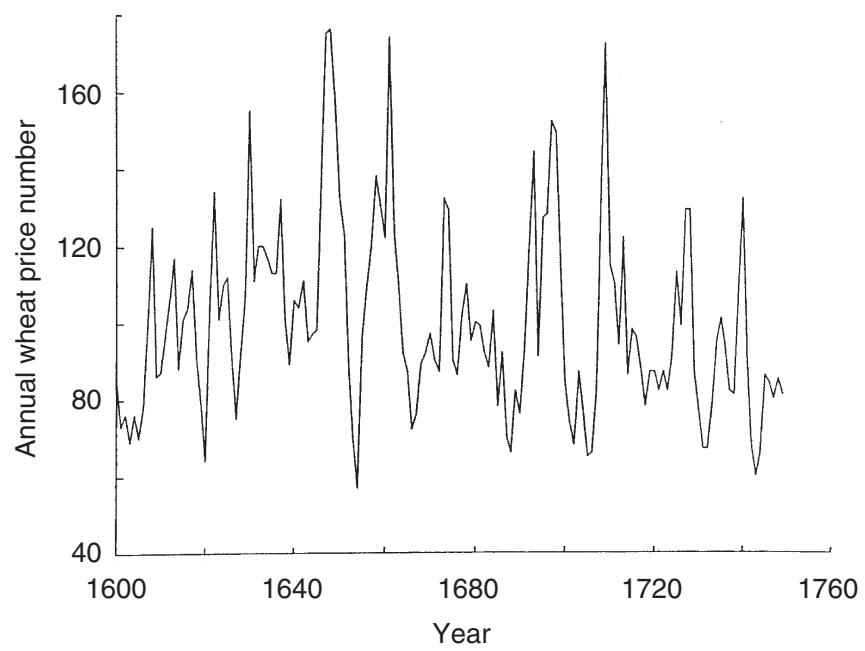

Fig. 2. Annual national wheat prices (wheat price number), 1600-1749. (After Bowden, 1967, 1985.)

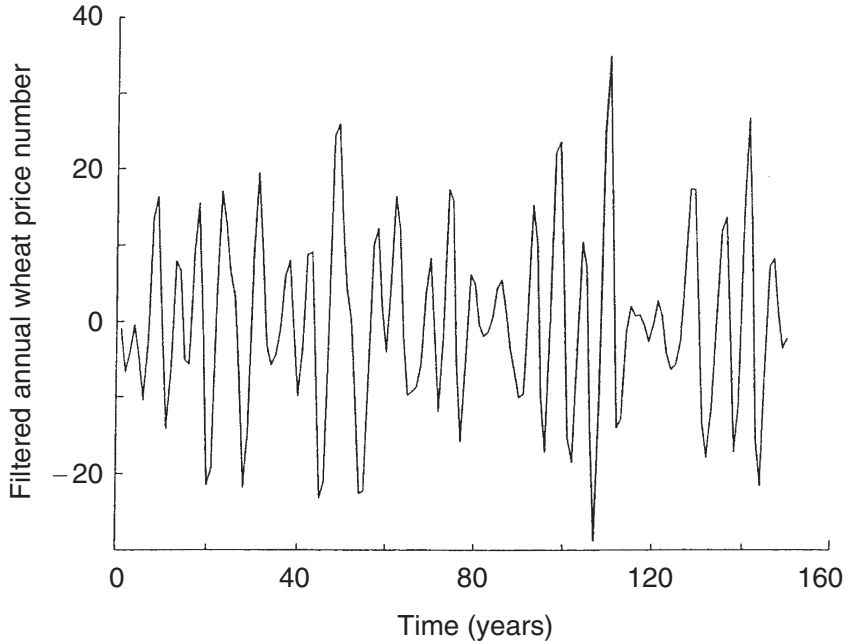

Fig. 3. Annual national wheat price, 1600-1749, filtered to reveal the short wavelength oscillation (filter window of $4-10$ years). (After Bowden, 1967, 1985.)

Modern agricultural economics in the developed world has a number of built-in stabilising influences but these conditions were largely missing in the sixteenth and seventeenth centuries (and in Third World countries today). The dramatic fluctuations in the staple food supply had to be endured as one of the penalties of a backward economic system (Scott \& Duncan, 2002).

The 5- to 6-year oscillation in wheat prices was not significantly correlated with weather conditions, but multivariate analysis reveals that prices were significantly influenced by the availability of grain in the preceding 1 or even 2 years. One bad harvest, by reducing the yield ratio to dangerously low levels, tended to generate another because of the scarcity of seed-grain, so that this effect was cumulative until the sequence was broken and the balance between bread-grain and seed-grain was restored. These are socalled autoregressive effects in which the grain price is strongly influenced by the price in the preceding 1 or even 2 years. In this way, an oscillation would be automatically built into the series and hence into the availability of food. An autoregressive term included in the multiple regression study (Scott \& Duncan, 1998) was highly significant $(P<0 \cdot 001)$ and a second autoregressive term was also significant $(P<0 \cdot 012)$, showing that the wheat prices in the 2 preceding years have detectable effects.

\section{Mortality oscillations in 404 English parishes: a metapopulation study}

The parish registers of England, which were kept from about 1550 until 1840, when they were superseded by civil registration, provide a wonderful source of population data. Wrigley \& Schofield (1981) studied 404 rural parishes from 1539 to 1871 and determined simple aggregated totals of annual burials (see Fig. 4).

Spectral analysis of this burial series for the years 1539-1719 reveals a significant $(P=0 \cdot 05) 6 \cdot 7$-year oscillation, which persisted into the nineteenth century, although it then became weaker. It is shown after filtering in Fig. 4 (b). 


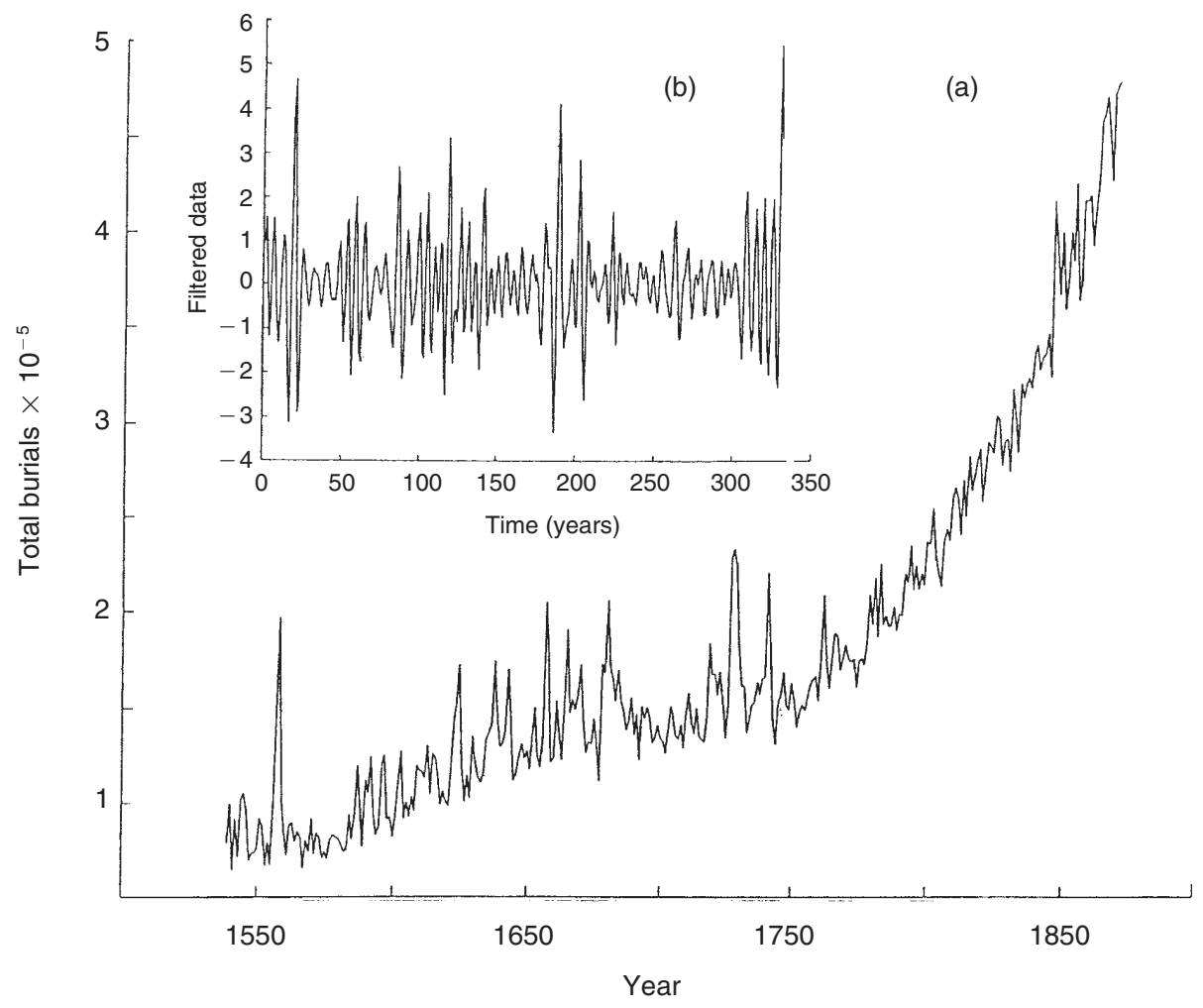

Fig. 4. (a) Annual burials (total burials $\times 10^{-5}$ ) in the 404 rural parishes in England, 1539-1873. Note the major mortality crises before 1750 and the change in the slope of the line thereafter. (b) Filtered annual burials, 1539-1873 (filter window of 4-10 years). (Data from Wrigley \& Schofield, 1981.)

This short wavelength oscillation in burials persisted, therefore, for 300 years and is detectable even when the data from 404 parishes are combined. We conclude that not only must this oscillation in mortality have been present in the majority of these small, separate, rural populations but also that (most importantly) they must have been synchronous (Scott \& Duncan, 1998).

We have seen that when wheat prices were high they caused hardship, famine and, ultimately, mortality and this is confirmed by a comparison of the filtered burial series with the filtered wheat prices, using the cross-correlation program. The two series were strongly and positively crosscorrelated over the period 1539-1838 with a lag of 0 or +1 years (see Fig. 5). To conclude, the 6- to 7-year oscillation in the burial series of rural England was exogenous and was driven by regular periods of malnutrition and hardship. The bulk of the population had, therefore, to contend with a general sub-optimal nutrition (deficient in animal protein, vitamins and minerals and lacking variety) superimposed on which was a marked oscillation in the price (and hence in the availability) of their staple cereal food (Scott \& Duncan, 2002).

\section{Nutrition and fertility}

Fertility can be regarded as the potential capability of a woman to bear children and it is of major importance in controlling human demography. The chronic malnutrition of the grain-based agricultural diet, usually with relatively little animal protein, had serious effects on the fertility of the general population, although these can be detected in pre-industrial England only with great difficulty.

Body fat has a key role in determining a woman's reproductive ability (Frisch, 1990, 1999, 2002). Women who are underweight experience disruption of their reproductive cycle, as shown by some ballet dancers, marathon runners

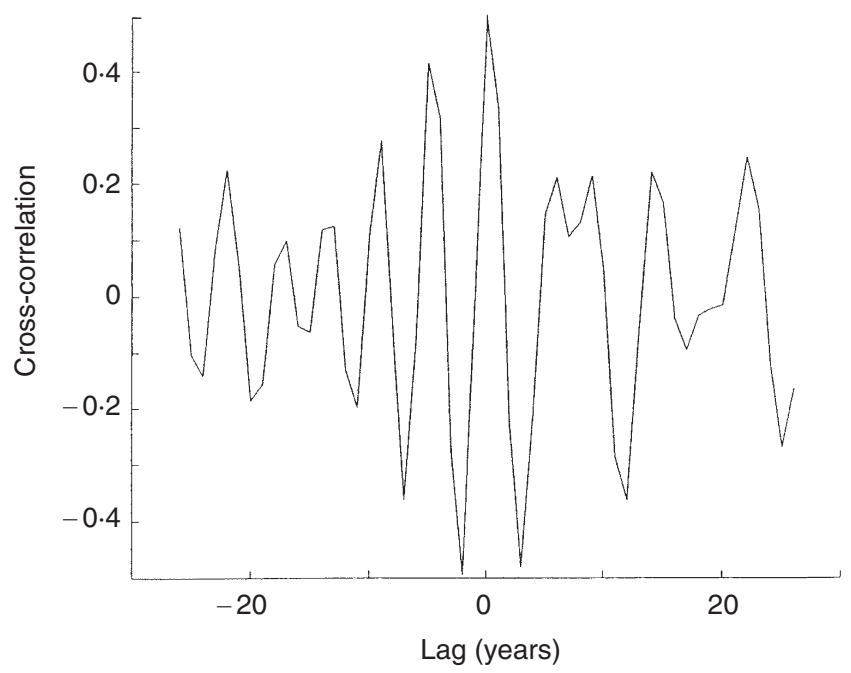

Fig. 5. Cross-correlation function: wheat prices $v$. annual burials in the 404 rural parishes in England, 1639-89. Cross-correlation $=0.5$ at zero lag, as shown by the peak at 0 years. 
and anorexic girls, who may stop menstruating; a very effective means of contraception. Indeed, moderate weight loss, in the range of $10-15 \%$, which is equivalent to losing one-third of the body fat, can result in the failure to menstruate because of hypothalamic dysfunction. Also, if excessive leanness occurs before the start of menstruation (the menarche), it may be delayed until as late as the age of 20 years. Consequently, a minimum weight-for-height has been predicted for the onset and maintenance of regular ovulatory cycles (Frisch, 1999).

The major function of a woman's white adipose tissue is the storage of about $16 \mathrm{~kg}$ fat, which is a highly efficient energy reserve equivalent to over $600 \mathrm{MJ}$. The development of copious stores of fat was probably very important for the evolution of homeothermy in birds and mammals which demands a much higher BMR. This reserve is to provide energy for a potential pregnancy and for about 3 months' lactation. Fat is the most labile component of body weight and therefore reflects environmental changes in food supplies more rapidly than other tissues (Frisch, 1999). In earlier times, when the food supply was scarce and fluctuated seasonally, stored fat would have been necessary for successful reproduction.

The body fat content is regulated by a negative feedback loop centred on the hypothalamus. Leptin, the $16 \mathrm{kDa}$ protein product of the $o b$ gene, is a hormone that is secreted by adipocytes. When released into the blood, it travels to the hypothalamus where there are leptin receptors involved in the control of appetite and energy expenditure. Leptin functions as one afferent signal in this system; increasing leptin levels normally result in a negative energy balance, whereas a decrease in the levels leads to a positive balance (although some fatter individuals may have higher leptin levels). Leptin is the signal that the brain uses to modulate female reproductive function (Frisch, 1999, 2002), so that, if a woman:

is obese, she has a greatly reduced fertility;

is overweight, she has a reduced fertility;

has normal body mass, she has normal fertility;

is underweight, she has a reduced fertility;

is seriously underweight, her fertility is essentially zero.

The message is clear; a woman who wants to maximise the chances of conception should keep her weight at the recognised optimum level. This makes good sense in evolutionary terms because this mechanism of controlling a woman's fertility ensures that she does not enter pregnancy without adequate fat reserves; an essential prerequisite for a successful outcome (Frisch, 2002). In pre-industrial England, the poor diet restricted the ability of women to lay down adequate fat reserves and so was a major factor in reducing their fertility.

However, the developed world today is facing an accelerating pandemic of obesity. We are now suffering from a surfeit of food. In the UK alone about 1000 individuals die prematurely per week from obesity or its complications; bowel and breast cancer, osteoarthritis, diabetes, hypertension and lung disease. Excessive eating raises levels of cholesterol, causing strokes and heart attacks (Bloom, 2003). We can see why this is happening. Man was designed by evolution to gain weight during the good times to tide him over periods when there was no food. There is no hungry season now and many individuals overeat all the year round from birth to old age.

\section{Hutterite women: the upper limit of fertility?}

The upper limit of fertility is set by the proportion of women who are engaged in childbearing, the length of the fertile period in women's lives and the speed at which they produce babies. A population that is maximising fertility will have all of the women married for all of the time during their reproductive years, will have early menarche and late menopause, and will have the shortest possible intervals between births. Hutterites of Western Canada and the USA come closest to these conditions among contemporary populations (Eaton \& Mayer, 1953). They are a well-nourished, healthy group of individuals with super-abundant food resources and modern medical care who desire maximally large families for religious and practical reasons. The total fertility rate represents the number of children who would be born to the average woman who survives through the childbearing years. The married Hutterite women achieve a total fertility rate of $10 \cdot 4$, the world record.

\section{Effects of chronic malnutrition}

How did the working classes of pre-industrial England fare with their monotonous and inadequate diet? They were mainly eating grain-based food, which would not readily allow the women to build up their fat stores. The community at Penrith, Cumbria in north-west England was living under marginal conditions from the sixteenth to the nineteenth centuries and was chosen as the study group (Scott \& Duncan, 1998). The families were divided into three social classes; the elites, tradesmen and subsistence farmers. A family reconstitution study (Duncan et al. 1992) enabled us to determine all the children born to each married woman and so it was possible to calculate the fertility for this population. Fig. 6 shows how a woman's fertility changed with her age in the elites (line B), tradesmen (line E) and subsistence farmers (line $G$ ). There are clear differences between the classes at Penrith, but all three have low marital fertility in their teenage years and early twenties. This is in very clear contrast with the well-nourished Hutterites (Wilson, 1984) whose fertility is very high in the twenties and falls steadily thereafter with age (Fig. 6, line A).

Marital fertility for the subsistence group at Penrith (line $\mathrm{G})$ has all the characteristics of a malnourished society; fertility at 20 years was less than one half that of the Hutterites, and the women did not reach their maximum until their late twenties. Even then, fertility was very low (Scott \& Duncan, 1999). This changing pattern of fertility with age shown by the subsistence group at Penrith closely follows that found in the poorly nourished population of Nepal today (see line F, Fig. 6).

The tradesmen group at Penrith had a better standard of living than the subsistence farmers, but their overall fertility was only slightly improved by reaching their peak at an earlier age (line E).

The elites (line B) were clearly different from the other two social groups at Penrith in that their age of maximum 


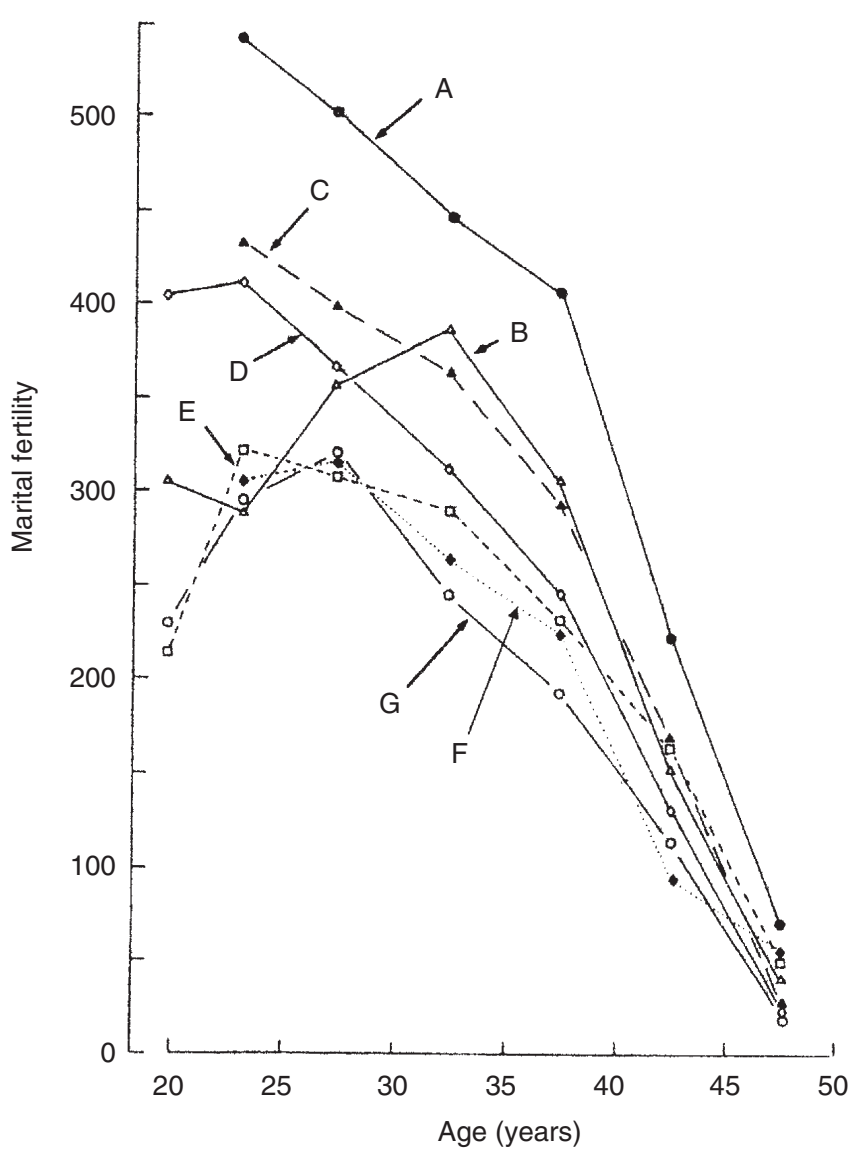

Fig. 6. Age-specific marital fertility rates (children born per 1000 women-years lived) for seven populations. Line $A(\bullet)$, Hutterites, 1921-30 (from Wilson, 1984); line B $(\Delta)$, elites at Penrith, Cumbria, England, 1600-1812; line $C(\mathbf{\Delta})$, average of four Waldeck villages of pre-industrial Germany, 1662-1849 (from Wilson, 1984); line D $(\diamond)$, average of twenty-five reconstituted English parishes, 1600-1824 (from Wrigley et al. 1997); line $\mathrm{E}(\square)$, tradesmen at Penrith, 1600-1812; line F $(\diamond)$, Nepal, 1977 (from Wilson, 1984); line G (O), subsistence class at Penrith, 1600-1812.

fertility was 5 years later and they had a considerably higher rate of fertility during the ages of 27-40 years, although it was below that of the Hutterites. But below the age of 27 years, the elites displayed the same subfertility that was characteristic of all the social groups at Penrith; indeed, their fertility level at the age of 23 years was below that of both the tradesmen and subsistence groups (Scott \& Duncan, 1999).

Thus, chronic malnutrition had a most important demographic effect by markedly lowering marital fertility during the teenage years and early twenties. This is also clearly shown by a study of twenty-six rural parishes in pre-industrial England, where the diet was predominantly grainbased (Fig. 6, line D), and by villages in pre-industrial Germany (Fig. 6, line C); but these communities enjoyed a better standard of living than that experienced at Penrith .

\section{Procreative power and demography}

Procreative power is the variation in the rate of childbearing with age. An early age at menarche for the Hutterites of
12-13 years is followed by completed physical growth by the age of 16 years (Fig. 7, line A), and their best physical fitness for procreation is reached by the end of their teenage years, after which there is a steady decline in fertility until the menopause which occurs in the fifth decade of life (Frisch, 1978). In contrast, the curve representing the procreative power of the women of mid-nineteenth century England (Fig. 7, line B) displays an overall sub-optimal level of fertility; menarche was at the later age of 15-16 years and there was a longer period of adolescent sterility than for the Hutterites. The best fitness for procreation was during the mid- to late-twenties and there was a steeper decline in fertility followed by an earlier age at menopause.

The overall age at the best fitness for procreation for the population at Penrith (Fig. 7, line C) lies between the ages of 27 and 32 years and this curve is well below that for the midnineteenth century population in England and the age of best fitness for procreation was 2-3 years earlier. The long period of adolescent sterility suggests that menarche is unlikely to have occurred earlier than the age of 17 or 18 years.

The earlier and higher level of the peak of fertility for the Hutterites, coupled with their longer reproductive span (the consequence of an early menarche and late menopause), has been explained by the effects of improved nutrition. In contrast, undernutrition, acting via a long period of adolescent sub-fecundity, reduced fertility for the mid-nineteenth century British population and a mean family size of only six to eight children was the result. A later age at sexual maturity and a shorter reproductive span among the worst-nourished women of Penrith meant fewer births and a considerably smaller family size of four children. With $50 \%$ of the children failing to reach maturity, the community experienced zero population growth over two centuries.

\section{Nutrition and pregnancy}

Pre-industrial England had apparently settled down and acclimatised to a diet largely based on grains. Superficially, it seemed, they could obtain just sufficient energy to sustain them for the heavy workload demanded by their agricultural lifestyle. They did not realise that fertility was well below the maximum possible and they accepted with resignation a seemingly never-ending series of deaths of their infants. Life expectancy was low but overall the population was growing, albeit slowly, as can be seen in Fig. 4. Unseen by anyone, malnutrition was having its, quite literally, deadly effects when a woman was pregnant and these effects on pregnancy continue right up to the present day. Nutrition of the mother can affect the development of the fetus, so causing abortions and infant deaths and compromising the health of the children and also, most worryingly, determining the diseases that will afflict them in later life. Even a short period of malnutrition during a woman's pregnancy can have serious repercussions and the deficiency of a key vitamin or micronutrient may be undetected, but nevertheless critical. Even more striking, it was found that girls who suffered from inadequate nutrition as a fetus and who were small at birth inevitably carry this handicap forward into the next and subsequent generations. Nutrition has had its most dramatic effects on human population dynamics via its undetected actions on women in pregnancy. 


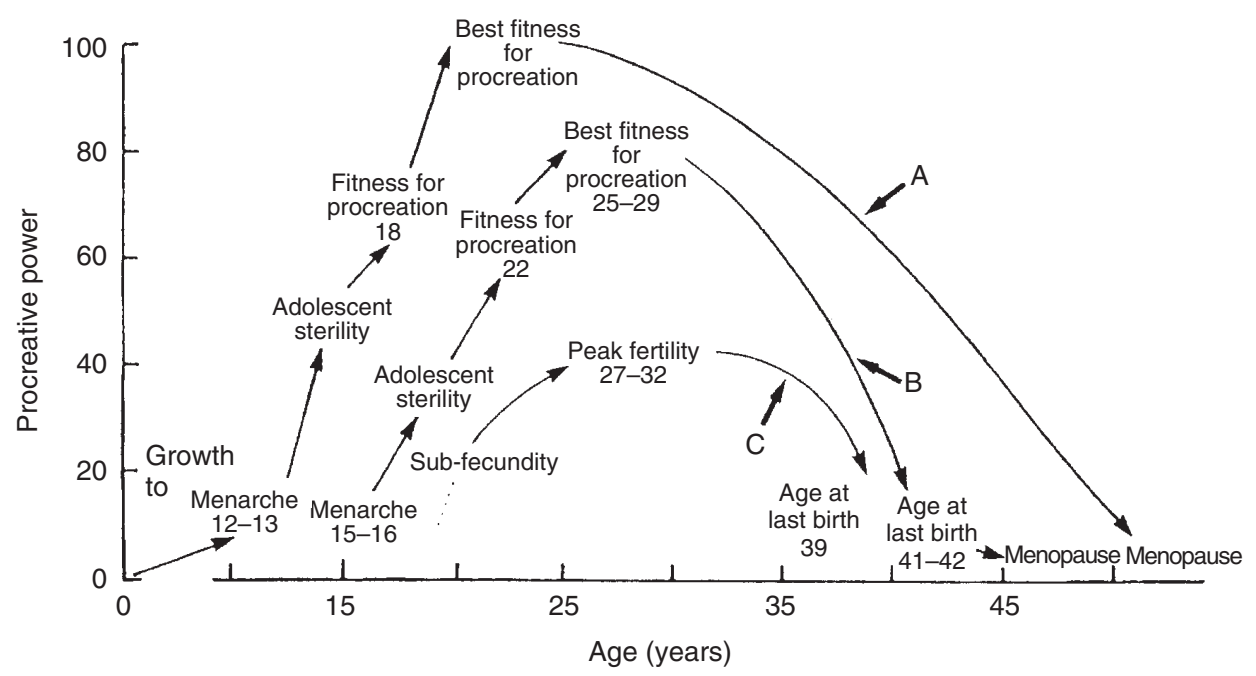

Fig. 7. Variation of procreative power (the rate of childbearing) with age. Line A, Hutterite women, 1930-50; line B, women in England and Scotland, 1850-70; line C, approximate curve for women in Penrith, Cumbria, England, 1600-1812. The maximum procreative power for the well-nourished, non-contracepting Hutterites is 100. Data for lines A and B from Frisch (1978) and for line C from Scott \& Duncan (2002).

These remarkable effects of malnutrition during pregnancy were carefully elucidated by Barker and his colleagues at Southampton (Barker et al. 1990; Barker \& Martyn, 1992; Barker, 1998, 1999a,b) who had access to a wonderful data series, which began in the early twentieth century in Hertfordshire. The midwives there recorded the birth weight and a full range of vital statistics of the babies born from 1911 onwards and then informed the local health visitor who went to the home at intervals throughout infancy and recorded development and illnesses.

The Southampton group then followed the subsequent health records of these children, their illnesses during adulthood and finally the causes of death. Some were still alive 70 years later and could be traced and examined. Thus, the Hertfordshire records made it possible to relate an individual's early growth to their health in later life; malnutrition of the fetus not only causes smaller babies and higher neonatal mortality, but also predisposes the adult to serious illnesses in later life, namely stroke, CHD, raised blood pressure and diabetes.

It is the fluctuating levels of food supply for the mother that can potentially have the most damaging effects on the health of the baby. Malnutrition can exert its effects before pregnancy, or when the placenta is being established, or during any of the 9 months of the life of the fetus in utero. Its specific effects on development are different for each of these time periods. The kidney, for example, is laid down during the last trimester of pregnancy, whereas the pancreatic cells continue to differentiate during infancy; undernutrition at different times in gestation has different effects. But these different ways of producing malnourishment of the developing fetus usually result in a baby with a low birth weight and these are most at risk. However, we still do not know with certainty what aspects of inadequate nutrition can be the most damaging to the developing fetus because programming effects were evident in babies within the normal range of birth weight.

\section{Proportionate small size at birth}

Some babies are proportionately small at birth; their length, head size and weight are reduced in the same proportion. Such babies establish a slow pattern of growth in early gestation and thereby avoid becoming disproportionate. Early slowing of the growth trajectory is a major adaptation to undernutrition because it reduces the subsequent demand for nutrients. Thus, in early intra-uterine life, undernutrition tends to produce small but normally proportioned infants, whereas at later stages of development it leads to selective organ damage and the infant is born disproportionate in size (McCance \& Widdowson, 1962, 1974). It is these disproportionate children, usually showing abnormal thinness, who are most at risk of developing serious illnesses in later life, particularly late-onset diabetes (Barker, 1998).

Today, there is a difference in fetal growth rates across the world; paradoxically, proportionate growth retardation is common in the less industrialised countries, while disproportionate growth retardation prevails in Westernised countries and the consequences are evident all around us. CHD was rare in Britain before the twentieth century, but is a major cause of death today. This illness occurs in Westernised populations where the level of nutrition lies between chronic malnutrition (when there is an early reduction in fetal growth) and nutrition at a level that allows adequate fetal nutrition (Barker, 1999b). The interacting factors are certainly complex but the predisposition to develop CVD following impaired fetal growth probably depends on a mismatch between fetal life and postnatal conditions, being most evident in individuals who experienced poor fetal growth and who were then exposed to an affluent lifestyle (including a Western dietary pattern) as adults.

Pre-industrial England, with its impoverished diet, probably resembled conditions in Third World countries today and their babies were small-sized (with a high risk of infant 
mortality), but were probably proportionate and so were not necessarily predisposed to serious illnesses later in adult life; of course, life expectancy was lower anyway.

\section{The fate of later generations}

From the point of view of population dynamics, perhaps the most truly remarkable finding of Barker and his colleagues was that undernourishment of a female fetus can have longterm, knock-on, intergenerational effects. Women who were small at birth are at twice the risk of having, in turn, babies of low birth weight who are also thin; these infants are found to be more likely to die during the perinatal period (Barker, 1998). In this way, the original birth weights of mothers have persistent effects and influence the birth weights of their children and of their grandchildren (Ounsted et al. 1986).

The consequences of this intergenerational effect for populations living under marginal conditions with a generally inadequate nutritional level are clear; these inevitable knock-on effects of low-birth-weight babies and high infant mortality would mean that, even with ameliorating conditions, it would be difficult to escape from the vicious circle of events that constrained population growth (Stewart et al. 1980).

\section{Exogenous cycles: a case study}

The adverse effects of malnutrition during pregnancy were readily detectable in children born in the early part of the twentieth century in Hertfordshire once Barker (1998) had had the seminal idea of correlating the health of adults with the midwives' records. The situation was much more serious for the mothers in pre-industrial England but the effects of malnutrition are much less readily detectable because of a complete lack of direct data for that time. Since the relationship between maternal and fetal nutrition is complex, it is not known, even for the twentieth century Hertfordshire study, what aspects of fetal nutrition are important, or how these relate to the maternal diet.

For pre-industrial England, we have only the indirect evidence of the wheat price and infant burial series available and so only generalised conclusions are possible. And yet interesting deductions can be made. The overall level of nutrition was sub-adequate but, as we have seen, superimposed were sharp fluctuations in the food supply, not only seasonally but also in the 6- to 7-year cycle in wheat prices. The fetus was at risk during the hungry season and during years when food prices were high.

The cycle in burials in the 404 parishes shown in Fig. 4 is compounded of infant, child and adult mortalities. In this section, we present an intensive case study of the interaction of the exogenous population cycles in the parish of Penrith, Cumbria using the methods of time-series analysis to determine the economic factors on which they are based. The thesis presented is that the oscillations in grain prices described earlier (p. 164), and the corresponding availability of the staple diet had profound but subtle effects on the population at Penrith and was one of the major factors in driving the short wavelength oscillations in deaths and indirectly in births.

Using a family reconstitution study, the annual burials were divided into deaths of infants, children and adults.
Spectral analysis of the burial series of children aged 1-14 years shows that a 5- to 6-year oscillation emerged in the sixteenth century that was closely associated and positively cross-correlated with a corresponding oscillation in wheat prices which appeared at the same time (see earlier; p. 167). This suggests that a rise in child deaths was associated with years of high wheat prices and the consequent malnutrition. The short wavelength oscillation in child deaths became more regularised after 1650 and spectral analysis shows that its periodicity was strongly established at 5 years. We have shown (Duncan et al. 1992, 1993, 1994a; Scott \& Duncan, 1998) that this cycle of child mortality was because of regular, lethal smallpox epidemics. Thus, the smallpox epidemics at Penrith were superimposed after 1650 on the pre-existing cycles of child mortality and the oscillatory tendency of their dynamics became phaselocked to the driving effects of increased susceptibility associated with high wheat prices.

Spectral analysis of the adult burial series at Penrith shows a short wavelength oscillation that was predominantly 5 years and was revealed after filtering (Fig. 8). It was positively cross-correlated with wheat prices from 1550 to 1650 but thereafter was more significantly associated with a cycle in the climatic conditions which had a wavelength of 11 years (Duncan et al. 1992; Scott \& Duncan, 1998).

Infant mortality at Penrith was high and, until the middle of the seventeenth century, $25 \%$ of the children died during the first year of life. After this time, infant mortality fell progressively, but this improvement was counterbalanced by rising childhood mortality from smallpox (see Table 2).

Using the family reconstitution study at Penrith, the annual infant burial series was subdivided into neonatal mortality (28 d post-baptism) and post-neonatal mortality (1-12 months of life) expressed as a percentage of baptisms. Both these mortality series were strongly coherent with wheat prices in the short waveband $(P<0 \cdot 001)$. With postneonatal mortality, the peaks tended to occur in years of high wheat prices when food shortages caused difficulties with satisfactory lactation and weaning. Neonatal mortality,

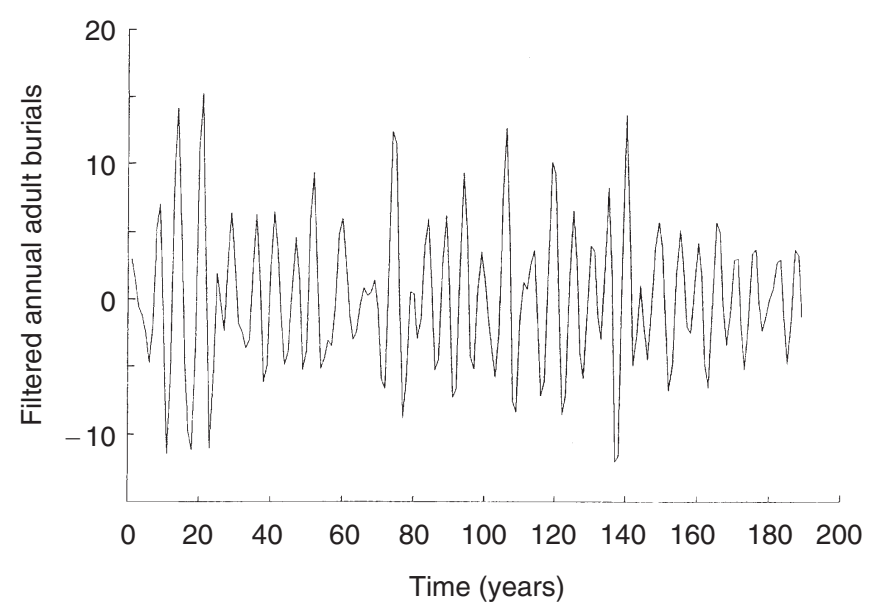

Fig. 8. Annual adult burials at Penrith, Cumbria, England, 1625-1812, filtered to reveal a short wavelength oscillation (filter window of $4-10$ years). Time (years) is after 1625. (After Duncan et al. 1992 and Scott \& Duncan, 1998.) 
Table 2. Life table burial rates (per 1000) for infants and children at Penrith, Cumbria, England (sexes combined), 1557-1812*

\begin{tabular}{lcccccc}
\hline Age groups (years) & \multicolumn{7}{c}{ Cohort } \\
\cline { 2 - 7 } & $1557-99$ & $1600-49$ & $1650-99$ & $1700-49$ & $1750-74$ & $1775-1812$ \\
\hline $0-1$ & 250 & 248 & 221 & 205 & 163 & 109 \\
$1-4$ & 98 & 132 & 141 & 158 & 154 & 119 \\
$5-9$ & 53 & 42 & 38 & 53 & 54 & 42 \\
$10-14$ & 33 & 21 & 27 & 24 & 26 & 54 \\
Percentage death rate & & & & & 40 & 32 \\
$\quad(0-14$ years) & 43 & 44 & 43 & 44 & 40 & 3 \\
\hline
\end{tabular}

*Burial rates derived from the family reconstitution study (Scott \& Duncan, 1998). Infant deaths were those occurring during the first 12 months after baptism. Children were aged 1 to 14 years.

on the other hand, showed predominantly a lag of +1 years, i.e. the peaks tended to occur in the year following high wheat prices, suggesting that these perinatal deaths were related to the malnutrition of the mother during pregnancy.

Spectral analysis also reveals a short wavelength oscillation in the baptism series at Penrith which had a periodicity of 5-8 years. This oscillation cross-correlates well with the oscillation in total burials over the period 1557-1700 $(P<0.01)$ but is completely out of phase, i.e. high annual burials correspond with low annual baptisms. This negative correlation between baptisms and total burials can be explored by using a simple matrix model of the population (Duncan et al. 1992; Scott \& Duncan, 1998). Thus, if a 5year oscillation in mortality is fed into the input, the model responds with a 5-year oscillation in births in the output, where the input and output are $180^{\circ}$ out of phase. The results suggest that the cycle in baptisms was not an immediate response to variations in grain prices and malnutrition, but was driven by fluctuations in mortality.

Migration also played an important part in maintaining the steady-state conditions, acting as an important component of the feedback control (Duncan et al. 1994b). Spectral analysis of the immigration index (Scott \& Duncan, 1998) shows a 5-year oscillation that is synchronous with a corresponding oscillation in adult deaths. Thus, rises in wheat prices caused concomitant rises in adult burials which then, in turn, promoted an influx of migrants who moved in to fill the vacant niches in the community. Immigration booms promoted rises in illegitimacy (Scott \& Duncan, 1997).

\section{Interactions between the different exogenous oscillations: a demographic overview}

The complex population dynamics at Penrith from 1550 to 1800 are summarised in Fig. 9. The clear oscillations in wheat prices, reflecting the availability of the major food, when superimposed on a generally poor level of nutrition, drove the separate mortality cycles. Fluctuating levels of severe malnutrition had their dominant effect via the mother in pregnancy and caused high neonatal mortality and sickly infants who then died in the first year of life. Only very gradually did the infant mortality at Penrith improve, hampered by the intergenerational effects of having small babies at birth.

Smallpox, a lethal disease, has been shown to contribute substantially to the cycles in child mortality (Duncan et al. 1993, 1994c) and the evidence suggests that the epidemics were triggered by the peaks in the oscillation in wheat prices (see Fig. 9). Initiation of an epidemic was critically dependent on the build-up of a sufficiently large pool of susceptible children by new births (see Fig. 9). A rise in adult mortality led to an increase in immigration as individuals moved in from smaller communities from the surrounding countryside to fill the available niches. They contributed to the maintenance of population numbers in this saturated habitat.

The oscillations in mortality acted together to trigger a cycle of births that was $180^{\circ}$ out of phase, i.e. it lagged by about 3 years. These new births contributed to an increased population size, and this population pressure acted as feedback to exacerbate mortality by reducing the food available to an already compromised society.

\section{Conclusions}

Man is evolutionarily adapted to the omnivorous hunter-gatherer diet. The thesis developed here is that the change to an agricultural lifestyle imposed on mankind a diet that was not completely satisfactory and, for the great bulk of the population, superimposed on this were regular and seasonal periods of malnutrition. This fluctuating, sub-adequate nutrition was the major factor that determined the levels of fertility and infant mortality and so had a profound, but not obvious, effect on human population dynamics. These demographic effects are most readily detected in a saturated habitat where the population is living under density-dependent constraints, as at Penrith, and Fig. 10 shows in summary how nutrition could control the dynamics via the diet of the mothers. At the centre is the malnutrition of the pregnant woman, upsetting the programming of the developing fetus and causing stillbirths and endogenous and neonatal mortality. Malnourishment of the fetus also caused small-sized disproportionate babies who could suffer from a number of problems:

deaths in post-neonatal infancy (Scott \& Duncan, 1998); susceptible infants who died from weaning diarrhoea (Scott \& Duncan, 2002);

susceptible children with an increased risk of dying from a range of infectious diseases (Scott \& Duncan, 1998);

predisposition to a range of diseases in later life, although this had marginal demographic effects in preindustrial populations with a low life expectancy (Barker, 1998);

if the small-sized neonate were a daughter, she would, irrespective of her nutrition in childhood, tend to 


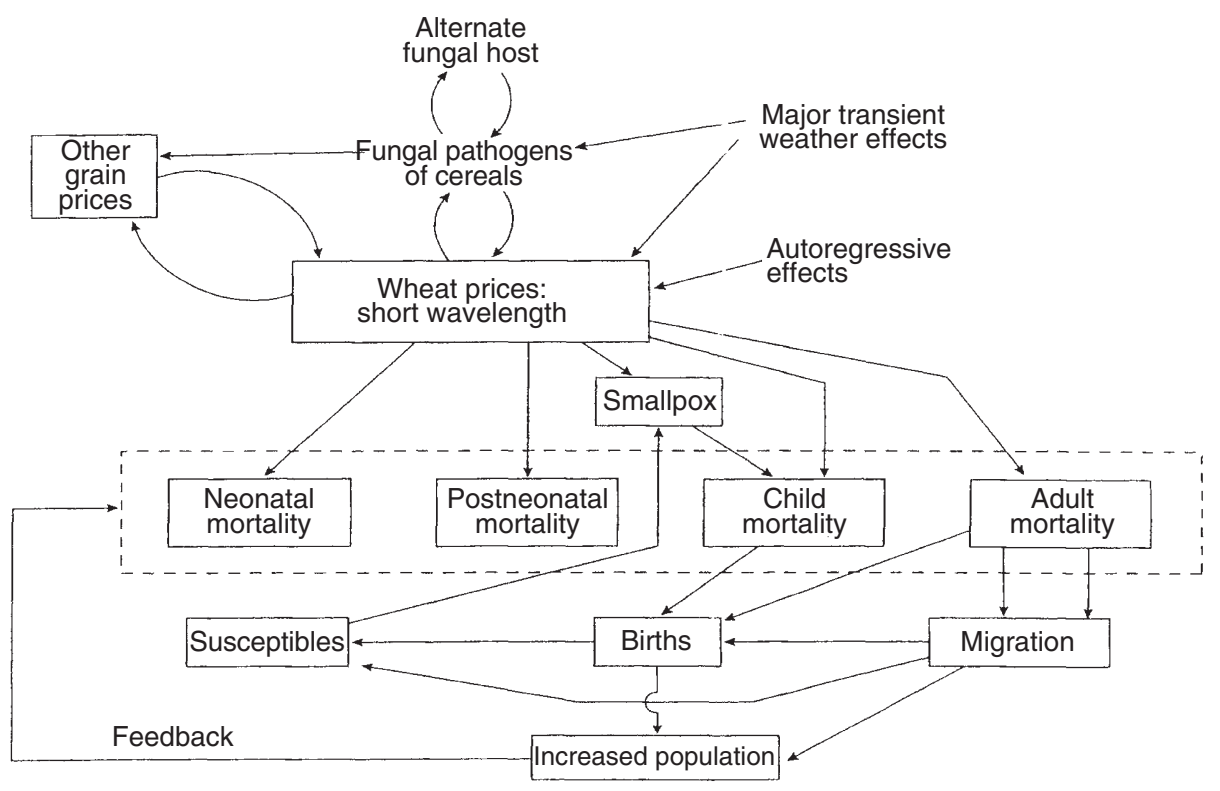

Fig. 9. Summary diagram of the suggested interaction of exogenous cycles at Penrith, Cumbria, England. The short wavelength oscillation that has been detected in the wheat price series by time-series analysis is shown in the upper part of the figure, together with the various factors that may interact with, and serve to drive it. The short wavelength oscillation in wheat prices is also subject to autoregressive factors. The oscillations in wheat prices represent cycles of malnutrition. The arrows indicate highly significant correlations $(P<0.01)$ and operate at zero lag except for neonatal mortality and migration (each at +1 years) and births which are negatively associated with total mortality. The feedback effect of increased population size on mortality is indicated. (After Scott \& Duncan, 2002.)

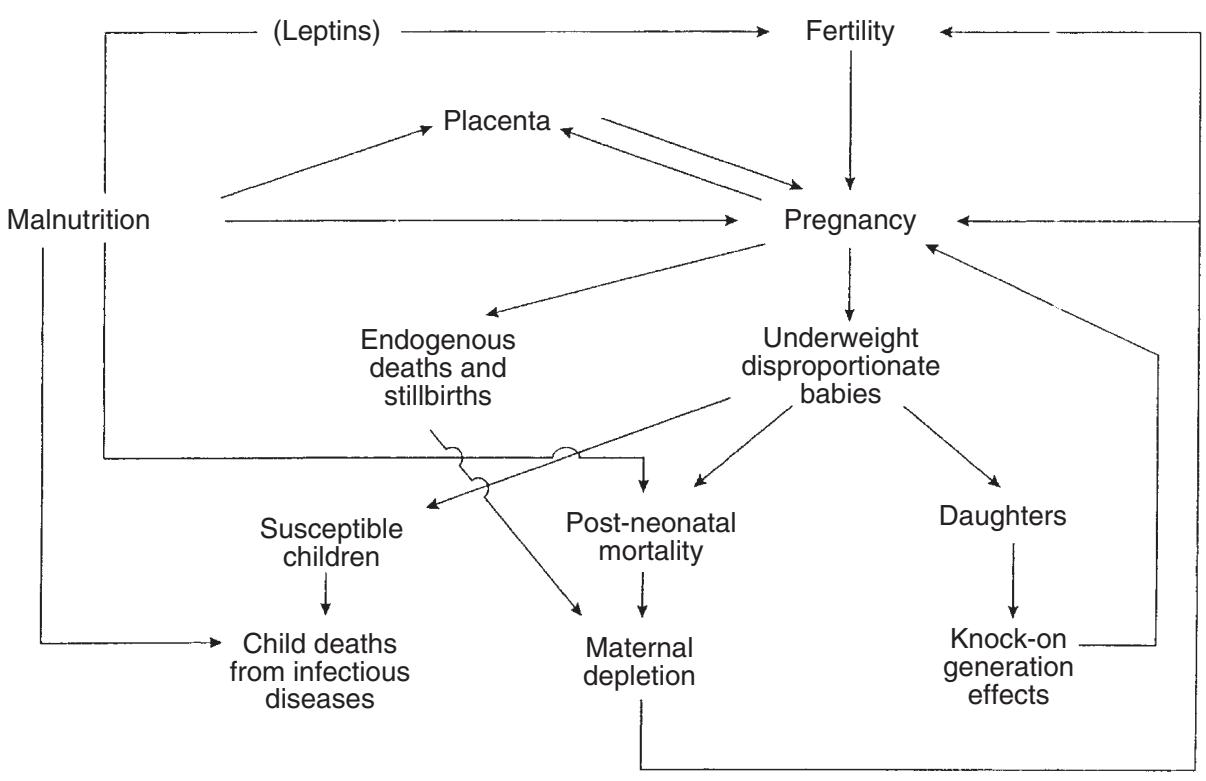

Fig. 10. Summary diagram to illustrate how malnutrition could regulate population dynamics via its subtle effects on fertility and pregnancy. Note the pivotal role of the pregnant woman. (After Scott \& Duncan, 2002.) 
produce, in turn, low-birth-weight daughters (see Fig. 10; Barker, 1998).

This last unexpected example of epigenetic inheritance is supported by recent studies with mice. In these studies, the coat colour of offspring was changed by simply giving females extra doses of four common nutrients, including folic acid and vitamin $\mathrm{B}_{12}$. Remarkably, the offspring were also less prone to obesity and diabetes than genetically identical mice whose mothers had not been given supplements. The differences were due to heritable changes in the activity of at least one gene in the offspring. These changes cannot be explained by changes in the DNA sequence. If the same phenomenon occurs in man, then what women eat, including supplements, during the formation of the egg and early embryo, could have an even more profound effect than anyone thought. Changes in gene activity could make their descendants more or less likely to suffer from a range of disorders, including obesity, cancer, diabetes and possibly even autism (Cohen, 2003).

The old adage 'You are what you eat' needs to be supplemented by 'You are what your mother ate.'

\section{References}

Barker DJP (1998) Mothers, Babies and Health in Later Life. Edinburgh: Churchill Livingstone.

Barker DJP (1999a) Fetal origins of cardiovascular disease. Annals of Medicine 31, 3-6.

Barker DJP (1999b) Fetal development and later disease. In Encyclopedia of Human Nutrition, pp. 785-792 [MJ Sadler, JJ Strain and B Caballero, editors]. San Diego, CA: Academic Press.

Barker DJP, Bull AR, Osmond C \& Simmonds SJ (1990) Fetal and placental size and risk of hypertension in adult life. British Medical Journal 301, 259-262.

Barker DJP \& Martyn CN (1992) The maternal and fetal origins of cardiovascular disease. Journal of Epidemiology and Community Health 46, 8-11.

Bloom S (2003) The fat controller. New Scientist 179, no. 2407, $38-41$.

Bowden PJ (1967) Agricultural prices, farm profits, and rents. In The Agrarian History of England and Wales, vol. IV, 1500-1640, pp. 593-695 [J Thirsk, editor]. Cambridge, UK: Cambridge University Press.

Bowden PJ (1985) Agricultural prices, wages, farm profits, and rents. In The Agrarian History of England and Wales, vol. V, 1640-1750, pp. 1-117 [J Thirsk, editor]. Cambridge, UK: Cambridge University Press.

Cohen MN (2000) History, diet and hunter-gatherers. In Cambridge World History of Food, pp. 63-71 [KF Kiple and KC Ornelas, editors]. Cambridge, UK: Cambridge University Press.

Cohen P (2003) You are what your mother ate. New Scientist 179, no. 2407, 14-15.

Duncan SR, Scott S \& Duncan CJ (1992) Time series analysis of oscillations in a model population: the effects of plague, pestilence and famine. Journal of Theoretical Biology 158, 293-311.

Duncan SR, Scott S \& Duncan CJ (1993) An hypothesis for the periodicity of smallpox epidemics as revealed by time series analysis. Journal of Theoretical Biology 160, 231-248.

Duncan SR, Scott S \& Duncan CJ (1994a) Predictions from time series analysis of the oscillations in parish register series. Journal of Theoretical Biology 168, 95-103.

Duncan SR, Scott S \& Duncan CJ (1994b) Determination of a feedback vector that generates a non-decaying oscillation in a model population. Journal of Theoretical Biology 167, 67-71.
Duncan SR, Scott S \& Duncan CJ (1994c) Modelling the different smallpox epidemics in England. Philosophical Transactions of the Royal Society 346B, 407-419.

Eaton JW \& Mayer AJ (1953) The social biology of very high fertility among the Hutterites. Human Biology 25, 206-264.

Frisch RE (1978) Population, food intake and fertility. Science 199, 22-30.

Frisch RE (editor) (1990) Adipose Tissue and Reproduction. Basel, Germany: Karger.

Frisch RE (1999) Body fat, menarche and fertility. In Encyclopedia of Human Nutrition, pp.777-785 [MJ Sadler, JJ Strain and B Caballero, editors]. San Diego, CA: Academic Press.

Frisch RE (2002) Female Fertility and the Body Fat Connection. Chicago, IL: University of Chicago Press.

Hoskins WG (1964) Harvest fluctuations and English economic history, 1480-1619. Agricultural History Review 12, 28-45.

Klein RG (1989) The Human Career: Human Biological and Cultural Origins. Chicago, IL: University of Chicago Press.

Larsen CS (2000) Dietary reconstruction and nutritional assessment of past peoples: the bioanthropological records. In Cambridge World History of Food, pp. 13-34 [KF Kiple and KC Ornelas, editors]. Cambridge, UK: Cambridge University Press.

Lee RB (1968) What hunters do for a living or how to make out on scarce resources. In Man the Hunter, pp. 30-48 [RB Lee and I DeVore, editors]. Chicago, IL: Aldine de Gruyter.

Lee RB (1969) !Kung Bushman subsistence: an input-output analysis. In Ecological Studies in Cultural Anthropology, pp. 47-79 [AP Vayda, editor]. Garden City, NY: Doubleday.

McCance RA \& Widdowson EM (1962) Nutrition and growth. Proceedings of the Royal Society of London 156B, 326-337.

McCance RA \& Widdowson EM (1974) The determinants of growth and form. Proceedings of the Royal Society of London 185B, $1-17$.

Nestle M (2000) Paleolithic diets: a sceptical view. Nutrition Bulletin 25, 43-47.

Ounsted M, Scott A \& Ounsted C (1986) Transmission through the female line of a mechanism constraining human fetal growth Annals of Human Biology 13, 143-151.

Scott S \& Duncan CJ (1997) Interacting effects affecting illegitimacy in preindustrial Northern England. Journal of Biosocial Science 29, 151-169.

Scott S \& Duncan CJ (1998) Human Demography and Disease. Cambridge, UK: Cambridge University Press.

Scott S \& Duncan CJ (1999) Nutrition, fertility and steadystate population dynamics in a preindustrial community in Penrith, Northern England. Journal of Biosocial Science 31 , 505-523.

Scott S \& Duncan CJ (2002) Demography and Nutrition. Oxford: Blackwell Science.

Shiell AW, Campbell-Brown M, Haselden S, Robinson S, Godfrey KM \& Barker DJP (2001) High-meat, low carbohydrate diet in pregnancy. Relation to adult blood pressure in the offspring. Hypertension 38, 1282-1288.

Stewart RJC, Sheppard H, Preece R \& Waterlow JC (1980) The effect of rehabilitation at different stages of development of rats marginally malnourished for ten to twelve generations. British Journal of Nutrition 43, 403-412.

Wilson C (1984) Natural fertility in pre-industrial England, 1600-1799. Population Studies 38, 225-240.

Woodburn J (1968) An introduction to Hadza ecology. In Man the Hunter, pp. 49-55 [RB Lee and I DeVore, editors]. Chicago, IL: Aldine de Gruyter.

Wrigley EA, Davis RS, Oeppen JE \& Schofield RS (1997) English Population History from Family Reconstitution 1580-1837. Cambridge, UK: Cambridge University Press.

Wrigley EA \& Schofield RS (1981) Population History of England and Wales, 1541-1871. London: Edward Arnold. 
https://doi.org/10.1079/NRR200491 Published online by Cambridge University Press 